\title{
A Percepção dos Trabalhadores das Técnicas Radiológicas Sobre Saúde e Segurança no Trabalho.
}

\author{
Coutinho, Isis Pereira; Lobo Neto, Francisco José da S. \\ Escola Politécnica Joaquim Venâncio/ Fiocruz — ISISPC24@GMAIL.COM
}

Este trabalho é fruto da pesquisa "Qualificação e Saúde do Trabalhador: a percepção dos trabalhadores técnicos em radiologia sobre as práticas de saúde e segurança no trabalho" para obtenção do título de mestre em educação profissional em saúde. o Objetivo do trabalho era identificar como o trabalhador percebe a influência da formação, escolar ou no trabalho, contribuindo para os processos de saúde e segurança no trabalho. a metodologia consistiu na elaboração de um questionário online através do Google Docs. a divulgação se deu através das "fanpages" e da "homepage" de uma escola de radiologia industrial no Rio de Janeiro e do Conselho dos Técnicos em Radiologia- CONTER. o questionário continha perguntas abertas e fechadas que abordavam aspectos da formação e do trabalho, com enfoque na área de proteção radiológica e os riscos do processo de trabalho dos técnicos. Além disto, foram realizadas duas entrevistas com aqueles profissionais de saúde que se convencionou denominar de "informantes chave". São pessoas que atuam na formação ou no serviço com estes trabalhadores e podem oferecer uma análise técnica sobre as temáticas da formação e da proteção radiológica. o resultado desta pesquisa encontra-se em análise preliminar, mas pode-se observar questões que orientam a reflexão sobre o campo da radiologia que se fazem necessários. a formação dos trabalhadores está a cargo do setor privado de ensino e, embora os trabalhadores digam que se formaram dentro do tempo esperado de 1 ano e 6 meses a 2 anos, segundo a entrevista, não necessariamente foi cumprida a carga horária de 1200 horas. Sobre a importância do tema de saúde e segurança ter estado presente na formação, não houve uma grande discrepância em considerá-los ineficazes. Porém é afirmado que no serviço e no estágio seu aprendizado sobre estas questões teve maior êxito. Além disso, há um número considerável de denúncias dos trabalhadores sobre problemas referentes à proteção radiológica tanto no setor privado quanto no setor público. no entanto, os trabalhadores do setor público apresentam maiores dificuldades com a infraestrutura fornecida para o serviço, alta burocracia impedindo mudanças nos setores, maquinário obsoleto, e sua não convocação para opinarem sobre mudanças necessárias. Também não demonstram confiança nos EPIs ( Equipamento de Proteção Individual) e não confiam em sua medição quando estes existem. Outro fator importante que os trabalhadores apontam como risco à sua saúde, está muito mais presente pela organização do trabalho, sobretudo mencionando a intensificação destes no serviço, o que acaba por influenciar o descaso do trabalhador com sua própria segurança ao realizar exames com radiação. na fala dos entrevistados, fica claro que uma proteção radiológica eficaz necessita da participação dos trabalhadores no processo de construção de saberes sobre o espaço de trabalho, treinamento e atualização do conteúdo de proteção radiológica no serviço e gestão que viabilize as condições necessárias para que estes trabalhadores possam garantir a sua própria proteção e dos colegas de trabalho, técnicos ou não.

Coutinho, Isis Pereira; Lobo Neto, Francisco José da S.. A Percepção dos Trabalhadores das Técnicas Radiológicas Sobre Saúde e Segurança no Trabalho.. In: Anais do Congresso Internacional de Humanidades \& Humanização em Saúde [= Blucher Medical Proceedings, num.2, vol.1]. São Paulo: Editora Blucher, 2014. ISSN 2357-7282

DOI 10.5151/medpro-cihhs-10494 